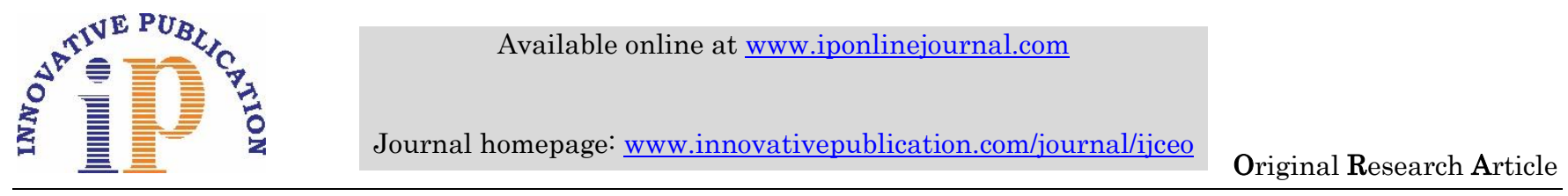

\title{
Outcome of penetrating keratoplasty in pseudophakic bullous keratopathy
}

\author{
Archana R. Thool ${ }^{1 *}$, Sweta Ambadkar ${ }^{2}$ \\ ${ }^{\mathbf{1}}$ Assistant Professor, ${ }^{2}$ Consultant, Dept. of Ophthalmology, ${ }^{\mathbf{1} J a w a h a r l a l ~ N e h r u ~ M e d i c a l ~ C o l l e g e, ~ W a r d h a, ~ M a h a r a s h t r a, ~}{ }^{2}$ Lion's Eye \\ Hospital, Aurangabad, Maharashtra, India
}

\section{Article Info}

Received: $4^{\text {th }}$ February, 2019

Accepted: $6^{\text {th }}$ May, 2019

Published Online: $9^{\text {th }}$ September, 2019

Keywords: Graft survival, Pseudophakic bullous keratopathy, Penetrating keratoplasty.

\begin{abstract}
Introduction: To study the outcome of penetrating keratoplasty in pseudophakic bullous keratopathy in terms of visual acuity, graft survival, complications and to identify prognostic factors.

Materials and Methods: This was a hospital based, prospective interventional study, which included 24 eyes of 24 patients with pseudophakic bullous keratopathy who underwent penetrating keratoplasty with interrupted sutures by single corneal surgeon. Eyes with posterior chamber IOL were retained, eyes with anterior chamber IOL were explanted without IOL exchange. Cases were followed upto 6 months. The outcome was assessed in terms of visual acuity, graft survival, complications and post keratoplasty astigmatism as depicted on corneal topography at the end of 6 months.

Results: Out of 24 cases, 5 cases were of regraft, 1 case was lost to follow up. Percentage of cases gaining visual acuity of $6 / 60$ or more was $60.86 \%$, clear grafts were $87 \%$, graft failure was $13 \%$. Incidence of post penetrating keratoplasty glaucoma was $30.43 \%$. Astigmatism ranged from 6 to 13 dioptres as a difference between simulate keratometric value of steep meridian and flat meridian on corneal topography at 6 months.

Conclusion: Penetrating keratoplasty in pseudophakic bullous keratopathy has good short term graft survival and moderate visual recovery. Retained posterior chamber IOL helped in better visual outcome. Glaucoma and immunological rejection were main causes for graft failure. Quality of donor tissue improves the outcome of penetrating keratoplasty.
\end{abstract}

\section{Introduction}

Normal cornea is transparent due its peculiar anatomical and physiological properties, forming major refracting surface of the eye. It can lose its ability to refract light due opacification or distortion of its contour. Individuals with corneal blindness are of relatively younger age group, hence in terms of total blind years, impact of corneal blindness is greater.

According to World Health Organization, 2009 report corneal blindness is the world's fourth leading cause of blindness. In India it accounts for $7 \%$ of total blindness. ${ }^{1}$

It is estimated that number of corneally blind individual in India will be around 10.6 million by $2020 .^{2}$

Cataract surgery is the major surgical intervention in ophthalmology. Corneal edema following cataract surgery with IOL is known as pseudophakic bullous keratopathy (PBK). Regardless of type cataract surgery with IOL implantation, continuing endothelial cell loss greater than usual $1 \%$ per year occurs in patient undergoing cataract extraction. Corneal edema usually develops when endothelial cell density falls below $500 / \mathrm{mm}^{2}{ }^{2}$

The incidence of PBK had increased progressively between 1980 - 1995 and become most frequent indication, around $26 \%$ for penetrating keratoplasty. ${ }^{3}$ The emergence of PBK as most common indication for penetrating keratoplasty (PK), correlates well with dramatic increase in number of cataract surgery with IOL implantation performed since early 1980. During early 1980's, use of Iris claw and rigid closed loop anterior chamber IOL's resulted in increased incidence of PBK. ${ }^{4}$ However there is decreasing trend because of obsolescence of older design and use of flexible open loop anterior chamber IOL. Also posterior chamber IOL has become the predominant form of implant used. Corneal edema with modern implant is likely to be due to surgical trauma and susceptible corneal endothelium rather than direct physical damage to corneal endothelium by the implant itself.

The incidence of PBK after intracapsular cataract extraction has been reported as high as $6 \%^{5}$ whereas after extracapsular extraction with anterior chamber IOL at one year to be $1.2 \%$, with Iris claw IOL $1.5 \%$ and with posterior chamber IOL to be $0.06 \% .^{6}$

Specular microscopy studies of patient who underwent cataract extraction with IOL have found endothelial cell loss which varies from $7 \%$ to $62 \%{ }^{8.9}$

\footnotetext{
*Corresponding Author: Archana R. Thool, Assistant Professor, Dept. of Ophthalmology, ${ }^{1}$ Jawaharlal Nehru Medical College, Wardha,
} Maharashtra, India

Email: drarchana8030@gmail.com

http://doi.org/10.18231/j.ijceo.2019.068 
Waltman et $\mathrm{al}^{9}$ found expectedly low endothelial cell count(less than 1000 cells $/ \mathrm{mm}^{2}$ ) in unoperated fellow eyes of $17 \%$ patients who had undergone PK for PBK in other eye suggestive of prior role of endothelial dystrophy.

Corneal grafting is among most successful forms of tissue transplantation, because of its immune privileged site. ${ }^{10} \mathrm{PBK}$ not responding to medical line of management can be benefited by PK with or without IOL explantation or IOL exchange.

\section{Material and Methods}

This was a prospective interventional study done at department of ophthalmology, Deenanath Mangheshkar Hospital and research centre, Pune. 24 patients with PBK presenting to us were studied from April 2008 to October 2008.

Informed consent was obtained from all subjects and procedure of the study was described to them. The study was carried out in accordance with the tenets of the Declaration of Helsinki.

\section{Inclusion Criteria}

1. Patients with PBK irrespective of type of IOL

2. Failed grafts, previous indication being PBK

\section{Exclusion Criteria}

1. Patients with retinal detachment, vitreous haemorrhage, etc as detected on B Scan.

2. Patients with inaccurate projection of rays.

\section{Pre Operative Evaluation}

All the patients were evaluated as follows

1. Detailed history including interval between cataract surgery and development of PBK. Interval between previous grafting and development of graft opacification in eyes with regraft.

2. Thorough general and systemic examination

3. Ocular examination: Recording of visual acuity, anterior segment examination on slit lamp of affected eye and other eye especially for endothelial changes by specular reflection. Endothelial cell count was not done due to unavailability of specular microscope. Also type and extent of corneal vascularisation. Fundus examination was done were media clarity permitted. IOP was done by Schiotz's tonometer because of irregular surface.

4. All patients were subjected to BScan for posterior segment evaluation due corneal opacification.

5. Investigations included were, Complete haemogram, blood sugar profile, ECG and urine examination. All patients had physician fitness before surgery.

\section{Donor Tissue Procurement}

1. Donor material was obtained by enucleation within 6 hours of death, with consent of relatives of the deceased.

2. Detailed medical, surgical and ocular history was obtained of the deceased to rule out any contraindication for use of donor material. Cause of death was ascertained in each case.

3. Blood samples were taken for HIV and hepatitis B.

4. Enucleation was carried out by harvesting whole globe under strict aseptic precautions. Enucleated eyes were immediately packed in glass bottles with cotton packing and were transported in ice packs and then stored at $4^{\circ} \mathrm{C}$ in refrigerator (moist chamber technique). Donor tissue was used within 48 hours.

5. Donor tissue with intrinsic eye diseases, previous intraocular surgery, ocular hypotony with iridocorneal touch, donor tissue of grade $\mathrm{B}$, donor age above 70 years were not used.

6. Grading of donor tissue: on slit lamp

a. Grade A: mild epithelial edema

b. Grade B+: mild epithelial edema and descement's folds at periphery

c. Grade B: marked epithelial edema, stromal edema, descement's folds till mid periphery

d. Grade B-: severe epithelial edema, epithelial denudation, marked stromal edema, descement's folds till centre.

e. Grade C: all of the above changes with more severity but iris and anterior chamber still visible.

f. Grade D: cornea totally hazy, details of anterior chamber not visible.

7. Also following parameters were noted, age of donor, death enucleation time, enucleation to surgery time and interval between development of PBK and PK.

\section{Surgical Technique}

1. Pre operative preparation: All patients received topical gatifloxacin $(0.3 \%)$ eye drops every 15 minutes for 2 hours prior to surgery. Patients with raised IOP were started on oral $250 \mathrm{mg}, 2$ stat or intravenous mannitol $20 \%$ in a dose of $1 \mathrm{mg} / \mathrm{kg}$ body weight 30 minutes prior to surgery. Betadine eye drops were instilled 5 minutes prior to surgery.

2. All surgeries were performed under local anaesthesia by peribulbar block. Anaesthetic agent used were, lignocaine $2 \%$ with adrenaline $(5 \mathrm{ml})$ along with bupivacaine $0.5 \%(3 \mathrm{ml})$ and injection hyaluronidase $75000 \mathrm{IU}$.

3. All surgeries were performed by single surgeon using standard technique.

Donor tissue was always harvested first, with graft host disparity of $0.5 \mathrm{~mm}$ and size of donor graft was $8 \mathrm{~mm}$

Donor graft was trephined from eyes and placed on Teflon block.

In eye with vascularisation, cauterization of vessels was done.

Recipient corneal button was trephined with $7.5 \mathrm{~mm}$ ensuring proper centration and tilt. Anterior chamber entered with 11 number blade and button was removed with curved corneal scissors. Synechiolysis was done whenever required with viscoelastic agent or iris repositor.

All eyes with posterior chamber IOL were retained after ensuring they are well centred. In 2 eyes IOL repositioning 
was done. Two eyes with anterior chamber IOL were explanted along with anterior vitrectomy and were left aphakic.

No eyes underwent IOL exchange. Peripheral button hole iridectomy was done in 2 cases with known glaucoma.

Donor graft was sutured to recepient bed with 10-0 nylon suture by placing 4 cardinal sutures at 12, 3, 6 and 9 o clock followed by 12 interrupted sutures. All bites were placed above the level of descement's membrane of equal length and equidistant from each other. All knots were buried on corneal side.

Intraoperatively all patients received intravenous $1 \mathrm{gm}$ cefotaxim and $8 \mathrm{mg}$ dexamethasone.

1. Post operatively all patients received oral cefotaxim $200 \mathrm{mg} \mathrm{BD}$ and combiflam for 5 days. Oral prednisolone $1 \mathrm{mg} / \mathrm{kg}$ body weight was started in all patients and was tapered every 7 days. Topical gatifloxacin $(0.3 \%)$, prednisolone $(1 \%)$ and carboxymethyl cellulose $(0.5 \%)$ were started. Eyes with raised IOP were started on timolol maleate $(0.5 \%) \mathrm{BD}$ or brimonidine $(0.2 \%)$ TDS or combination of both.

2. All cases were reviewed biweekly for 1 week, weekly for 1 month, fortnightly for 3 months and monthly for 6 months for visual acuity, graft clarity and IOP check.

3. Post operative graft edema was graded as E1 -mild iris details seen, E-2 moderate iris details hazy and E-3 severe iris details unclear.

4. One patient had IOP which was medically uncontrolled, hence treated with diode laser photocoagulation $270^{\circ}$ at 6 months.

5. 4 cases had immunological graft rejection during follow up period. These cases were treated with intravenous methylprednisolone pulse therapy, $1 \mathrm{gm} /$ per day for 3 days followed by oral prednisolone $1 \mathrm{mg} / \mathrm{kg} /$ body weight in tapering dose. One case recovered while 3 had graft failure and were considered for regrafting.

6. Corneal topography was done in all patients at 6 months. Dioptric power closest to $3 \mathrm{~mm}$ optical zone at steepest and flat meridian were selected and difference between simulate $\mathrm{K}$ value was taken as amount of astigmatism in dioptres.

\section{Results}

1. The study included 24 patients of PBK, which followed for a period of 6months expect for 1 who was lost to follow up after 4 months.

2. All patients were referred cases, hence details of cataract surgery were unavailable. All these cases had undergone either small incision cataract surgery or phacoemulsification as seen clinically.

3. Agewise distribution, 6 patients were in the range of 50 to 60 years, 10 in the range of 61 to 70 and 8 between 71 to 80 years.

4. Genderwise, 12 were females and 12 were males.

5. Out of 24 patients, 5 cases were of regraft who had undergone PK for PBK.

6. 2 patients were known cases of glaucoma and were medically controlled.
7. 10 patients showed guttate changes on endothelium of other eye on slit lamp.

8. 14 cases had superficial and deep vascularisation in various quadrants.

9. Interval between cataract surgery and development of PBK ranged from 4 months to 5 years.

10. Interval between $\mathrm{PK}$ and graft failure in cases with regraft ranged from 7 months to 2 tears.

11. Interval between PBK and PK in our study ranged from 3 months to 19 months.

12. Interval between enucleation and use of tissue ranged from 5 hours to 12 hours in our study.

13. Preoperatively 22 cases had posterior chamber IOL and 2 had anterior chamber IOL.

14. 22 cases underwent PK with retained IOL while 2 had IOL explantation. No IOL exchange was done.

Table 1: Distribution of patients according to preoperative visual acuity

\begin{tabular}{|l|c|}
\hline \multicolumn{1}{|c|}{ Preoperative visual acuity } & No. of cases \\
\hline HM, PL, PR accurate & 7 \\
\hline HM, PL, PR accurate to FC 1 meter & 15 \\
\hline FC 1 meter to 6/60 & 2 \\
\hline
\end{tabular}

Table 2: Distribution of patients according to postoperative visual acuity

\begin{tabular}{|c|c|}
\hline Postoperative visual acuity & No. of cases \\
\hline$<6 / 60$ & $9(39.13 \%)$ \\
\hline $6 / 60$ to $6 / 24$ & $12(52.17 \%)$ \\
\hline$>6 / 24$ & $2(8.7 \%)$ \\
\hline
\end{tabular}

Table 3: Distribution of patients according to graft survival at 6 months

\begin{tabular}{|c|c|c|c|}
\hline Graft clarity & Non Regraft & Regraft & Total \\
\hline Clear & 17 & 3 & $20(87 \%)$ \\
\hline Graft failure & 1 & 2 & $3(13 \%)$ \\
\hline
\end{tabular}

Table 4: Postoperative glaucoma $(30.43 \%)$

\begin{tabular}{|c|c|}
\hline Postoperative glaucoma & No of cases \\
\hline Medically controlled & $6(85.71 \%)$ \\
\hline Cyclophotocoagulation & $1(14.29 \%)$ \\
\hline
\end{tabular}

1. 2 cases had cystoids macular edema and 2 cases had age related macular degeneration.

2. Posterative astigmatism ranged from 6 to 13 diopters derived as difference between keratometric value of steep and flat meridian measured on corneal topography.

\section{Discussion}

PBK is chronic corneal edema caused by endothelial decompensation and resulting epithelial bullae in pseudophakic eyes. For visual rehabilitation and symptomatic cases of PBK, PK remains the only definitive treatment. 
PBK is generally regarded as moderate to good indication for PK. Survival of graft in PBK has been extensively studied in past. ${ }^{11,12}$

We conducted this study in our institute to study the outcome of PK in 24 eyes with PBK at the end of 6 months. The degree of success was assessed by number of patients gaining visual acuity of $6 / 60$ or more and percentage of grafts remaining clear at 6 months. Complications in form of post operative glaucoma, graft rejection and graft failure and post PK astigmatism were assessed. 22 eyes out of 24 had posterior chamber IOL and 2 had anterior chamber IOL.

IOL itself may not be the sole factor in causation of PBK. Other potential causes includes excess surgical manipulation, surgical trauma to endothelium, raised intraocular pressure post operative, persistent low grade chronic uveitis, displaced IOL. ${ }^{13}$ Pre existing endothelial dystrophy is another factor unrelated to IOL for early endothelial decompensation following cataract extraction with IOL implantation. ${ }^{14}$

Interval between development of PBK and cataract surgery was less than 9 months in 7cases in this study, suggestive of excess surgical handling leading endothelial decompensation. Raised intraocular pressure on presentation was seen in 5 cases, of which 2 were known cases of open angle glaucoma. Raised intraocular pressure could be the cause of endothelial decompensation post cataract surgery in these cases. 5 cases were of regraft, original indication being PBK. In these cases interval between previous PK and graft opacification ranged from 7 months to 2 years. Synechiolysis was done in 2 cases during PK, suggestive of post operative uveitis following cataract surgery leading to endothelial decompensation. In 2 cases IOL were decentered, hence IOL repositioning was done during PK, both were posterior chamber IOL and were retained.

In our study all donor tissue were of age less than 70 years and only grade A and B+ graft obtained within 6 hours of death were used.

The IOL can be retained if well centred, explanted or exchanged with another IOL. ${ }^{15}$ Components of anterior segment reconstruction include anterior vitrectomy, gonioplasty and iridoplasty. Anterior vitrectomy reduces incidence cystoids macular edema and prevent decentration of IOL by vitreous strand. ${ }^{12}$ In accordance with previous study all posterior chamber IOL were retained and both anterior chamber IOL were explanted and eyes were left aphakic. No cases had IOL exchange.

Postoperaively all cases were followed upto 6 months, except 1 who was lost to follow up after 4 months.

The visual recovery after PK is affected by complex inter-relationship of many factors, including corneal healing, age of patient, gradual diminishing astigmatism, decrease in cystoids macular edema, graft thickness and inflammation on long term follow up ${ }^{[16]}$. In our study visual acuity of $6 / 60$ or better with clear graft at 6 months was considered as criteria for successful corneal grafting.

In our study, 9 cases $(39.13 \%)$ had visual acuity less than $6 / 60,12$ cases $(52.17 \%$ ) had visual acuity between $6 / 60$ to $6 / 24$ i.e moderate visual recovery. Only 2 cases $(8.69 \%)$ had visual acuity of more than $6 / 24$. Thus 14 out of 23 cases $(60.86 \%)$ were optically successful. This study compares well with previous studies with respect to visual recovery. ${ }^{11,12,15,17}$ In cases with poor visual recovery, 2 had developed cystoids macular edema as seen on optical coherence tomography, 2 eyes had age related macular degeneration of which 1 was lost to follow up after 4 months. One patient developed central retinal vein occlusion. 2 cases had poor visual recovery due to advanced glaucomatous damage. Presence of retinal pathology like ARMD and CME are known causes for poor visual recovery. ${ }^{11,16,17}$

In our study $20(86.95 \%)$ out of 23 grafts remained clear at the end of 6 months. It compares well with other studies. ${ }^{11,12,15,17}$

In our study 4 cases developed immunological endothelial rejection. All these were treated with intravenous methylpredinosolone pulse therapy. Of these, 1 recovered the rejection episode, while 3 eventually failed. Out of these 3 cases, 2 were cases of regraft. Regraft is known risk factor for graft rejection. There were no cases of primary graft failure.

Factors which influenced good graft survival in our study would be, use of good quality donor tissue, less enucleation to surgery time, meticulous surgery and close but shorter duration of follow up.

Post PK glaucoma is one of the common cause of graft failure and visual loss. ${ }^{18}$ in our study 7 cases had raised IOP. This compares well with other studies. ${ }^{11,12,17,18} 6$ cases were controlled medically with timolol maleate $(0.5 \%)$ or brimonidine $(0.5 \%)$ or combination of both. 1 case required trans sclera cyclophotocoagulation with diode laser $(810 \mathrm{~nm})$ $270^{\circ}$.

Post PK astigmatism is associated with poor visual recovery, tear film instability and asthenopic symptoms. ${ }^{19,20}$ Astigmatism ranged from 6 to 13 diopters in our study.

\section{Conclusion}

1. PK in PBK is associated with good short term survival.

2. Retained posterior chamber IOL resulted in functional visual recovery.

3. Good quality of donor tissue resulted in better graft survival.

4. Visual recovery was moderate because of high astigmatism.

5. Causes of poor visual recovery were graft failure, macular pathology and glaucoma.

6. Causes of graft failure in our study were immunological endothelial graft rejection and glaucoma.

\section{Limitation \\ 1. Small sample size \\ 2. Shorter duration of follow up.}

Source of Funding: None.

Conflict of Interest: None. 


\section{References}

1. Gullapalli N Rao. Cornea and blindness. Indian J Ophthalmol 1994;42(4): 169 .

2. Rajesh Sinha, Namarata Sharma, Rasik Vajpayee. Corneal blindness - present status. Cataract and Refractive Surgery Today. 2005;59-61.

3. Noemi L, Vera O Kowal, Elisabeth J Cohen, Christopher J, Rapuano, Janice A et al. Indications for penetrating keratoplasty and associated procedures. 1989-1995. Cornea. 1997;16(6); 623-9.

4. Patrick S, Carina K, Marie J Tassignon. Visual acuity after penetrating keratoplasty for pseudophakic and aphakic bullous keratopathy. J Cataract Refractive Surg 2003;29;482-6.

5. Steven B Koieng, Richard O Schultz. Penetrating keratoplasty for pseudophakic bullous keratopathy after extracapsular cataract extraction. Am J Ophthalmol 1998;105;348-53.

6. Stark WJ, Worthen DM, Holladay JT et al. The FDA report on intraocular lenses. Ophthalmol 1983;90;311-7.

7. Binkhorst C D, Nygaard P Nad Loones. Specular microscopy of the corneal endothelium and implant surgery. Am J Ophthalmol 1978;85;597.

8. Bourne W.M and Kaufman H. E. Endothelial damage associated with intraocular lenses. Am J Ophthalmol $1976 ; 81 ; 482$.

9. Waltman SR. Penetrating keratoplasty for pseudophakic bullous keratopathy. Arch Ophthalmol 1981; 999; 415-6.

10. Smolin and Thoft's, Stephen Foster, Dimitri Azar, Claes Dholman. The cornea; Scientic foundation and clinical practice. $4^{\text {th }}$ edition (Lippincott Willliams \& Wilkins). 1-55, 94-97, 133-136,953,986.

11. Roger F, Meyer and Sugar A. Penetrating keratoplasty in pseudophakic bullous keratopathy. Am J Ophthalmol 1980;90;677-81.
12. Agarwal V, Vagh MM, Sangwan V, Rao GN. Penetrating keratoplasty for pseudophakic bullous keratopathy. Indian $J$ Ophthalmol 1994;42(2):75-80.

13. Kwartz J, Leatherbarrow B, P Dyer A E A Ridgway, A B Tullo. Penetrating keratoplasty for pseudophakic corneal edema. Br J Ophthalmol 1991;79;435-8.

14. Arentsen JJ, Laibson PR. Surgical management of pseudophakic corneal edema, complications and visual results following penetrating keratoplasty. Ophthalmic Surg 1982;13;371-3.

15. Michael Insler, Craig J, Herbert E Kaufman. Visual results after keratoplasty in patients with posterior chamber intraocular lenses. Am J Ophthalmol 1988;106(1);72-6.

16. Francis W, Price Jr, William E, Whitson, Ronald G, Marks. Progression of visual acuity after penetrating keratoplasty. Ophthalmol. 1991; 98(8):1177-85.

17. Sugar A. An analysis of corneal endothelial and graft survival in pseudophakic bullous keratopathy. Trans Am Ophthalmol Soc. 1989; LXXXVII; 87;762-801.

18. Dada T, Agrawal A, Minudath KB, vanathi M, Choudhary S, Gupta $\mathrm{V}$ et al, Post penetrating keratoplasty glaucoma. Indian J Ophthalmol 2008;56;4; 269-77.

19. Scott S, Elisabeth J Cohen, Kent G, Land Peter R, Laibson. Corneal topography for selective suture removal after penetrating keratoplasty. Am J Ophthalmol 1991;112;657-65.

20. Perry S, Binder. The effect of suture removal on post keratoplasty astigmatism. Am J Ophthalmol 1988;105;637-45.

How to cite this article: Thool AR, Ambadkar S. Outcome of penetrating keratoplasty in pseudophakic bullous keratopathy, Indian J Clin Exp Ophthalmol. 2019;5(3):282-6. 